\title{
Infected with Plasmodium berghei K173 \\ Analysis of Spleen Histopathology, Splenocyte composition and Hematological Parameters in Mice
}

Huajing Wang a,b, Shuo Li ${ }^{\text {a,b }}$, Zhao Cui a, Tingting Qin ${ }^{\text {a,b }}$, Hang Shi ${ }^{a}$, Ji Ma ${ }^{\text {a,b }}$, Lanfang Li a , Guihua Yu, Tingliang Jiang a,b and Canghai Li ${ }^{\text {a* }}$

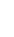

${ }^{a}$ Tang Center for Herbal Medicine Research, China Academy of Traditional Chinese Medical Sciences, Beijing, China

b Artemisinin Research Center and Institute of Chinese Meteria Medica, China Academy of Traditional Chinese Medical Sciences, Beijing, China

* Correspondence to: Dr. Canghai Li, Tang Center for Herbal Medicine Research, Institute of Chinese Materia Medica, China Academy of Chinese Medical Sciences, No. 16 Dongzhimen Nanxiaojie, Dongcheng District, Beijing 100700, China. Tel: (+86) 10-6404-1008, Fax: (+86) 10-6404-1008, E-mail: chli@icmm.ac.cn

ABSTRACT Malaria is a fatal disease that presents clinically as a continuum of symptoms and severity, which are determined by complex host-parasite interactions. Clearance of infection is believed to be accomplished by the spleen and mononuclear phagocytic system (MPS), both in the presence and absence of artemisinin treatment. The spleen filters infected RBCs from circulation through immune-mediated recognition of the infected RBCs followed by phagocytosis. Using different strains of mice infected with $P$. berghei K173 (PbK173), the mechanisms leading to splenomegaly, histopathology, splenocyte activation and proliferation, and their relationship to control of parasitemia and host mortality were examined. Survival time of mice infected with PbK173 varied, although the infection was uniformly lethal. Mice of the C57BL/6 strain were the most resistant, while mice of the strain ICR were the most susceptible. BALB/c and KM mice were intermediate. In the course of PbK173 infection, both strains of mice experienced significant splenomegaly. 
Parasites were observed in the red pulp at 3 days post infection in all animals. All spleens retained late trophozoite stages as well as a fraction of earlier ring-stage parasites. The percentages of macrophages in infected $\mathrm{C} 57 \mathrm{BL} / 6$ and $\mathrm{KM}$ mice were higher than uninfected mice on 8 dpi. Spleens of infected ICR and KM mice exhibited structural disorganization and remodeling. Furthermore, parasitemia was significantly higher in KM versus C57BL/6 mice at 8 dpi. The percentages of macrophages in ICR infected mice were lower than uninfected mice, and the parasitemia was higher than other strains. The results presented here demonstrate the rate of splenic mechanical filtration and the splenic macrophages likely contribute to an individual's total parasite burden. This in turn can influence the pathogenesis of malaria. Finally, different genetic backgrounds of mice have different splenic mechanisms for controlling malaria infection.

KEYWORDS Malaria, control infection, spleen filtration, splenocyte

Plasmodium falciparum parasitescause lethal infections worldwide, especially in Africa (1). Reducing this disease burden continues to rely heavily on the availability and proper use of effective antimalarial drugs. Artemisinin and its derivatives are sesquiterpene lactones with potent activity against nearly all blood stages of $P$. falciparum. There is a natural and complex variation in the pathogenesis and clinical presentation of malaria, which is influenced by host age, immunity and genetic background, as well as by environmental conditions and parasite genetics $(2,3)$. Host immunity and genetic factors are estimated to account for one quarter of the total variability in malaria severity $(4,5)$. Host defense mechanisms such as removal of circulating parasites by the spleen and mononuclear phagocytic system (MPS) are thought to play a major role in rapid control of infection (6), in the presence or absence of artemisinin treatment (7).

The function of the spleen is to remove senescent erythrocytes (RBCs) and circulating foreign material such as bacteria or cellular debris (8). The structure of the spleen is complex with 2 overlapping blood circulations - a rapid flow by-pass, called 
the fast closed circulation, which accommodates roughly $90 \%$ of the splenic blood flow (100-300 $\mathrm{mL} / \mathrm{min}$ in a healthy adult), and a slow open circulation in which the blood is filtered through narrow inter-endothelial slits $(9,10)$. In the slow open microcirculation, RBCs navigate through the cords of the red pulp before returning to the vascular beds by squeezing between endothelial cells in the sinus walls (11-13). Crossing splenic inter-endothelial slits poses the greatest demand on RBC deformability in the body (14) and is believed to result in the retention of less malleable RBCs or in removal of intraerythrocytic bodies. In malaria, the spleen filters infected RBCs from circulation by physical selection as well as immune-mediated recognition and phagocytosis of infected RBCs (15). These processes play a central role in the clearance of circulating malaria parasites (6). The rate of splenic mechanical filtration may be one factor affecting an individual's total parasite burden and the pathogenesis of malaria. Understanding the role of the spleen in host defense may shed additional light on the variation in human susceptibility to malaria and offer insights into possible mechanisms of malaria pathogenesis.

In the present study, the host defense against blood-stage malaria was examined by using different strains of mice infected with P. berghei K173 (PbK173), a rodent-lethal strain of malaria. Parasitemia and survival were measured to monitor the course of infection in C57BL/6, BALB/C, ICR, and KM mice. Since C57BL/6 mice were found to be more resistant to this infection, parameters indicative of a protective host response to infection were also characterized in the four strains mice. These included splenomegaly, histopathology, splenocyte subsets, hematological parameters.

\section{RESULTS}

\section{Progression of infection with PbK173 in mice}

Mice (18 22g) were purchased from Weitonglihua, and were inoculated with $10^{7} \mathrm{P}$. berghei K173 infected erythrocytes in $200 \mu \mathrm{L}$ of sterile saline buffer i.p. Mice were monitored daily for any signs of malaria, including parasitemia and behavioral changes, compared to uninfected controls. 

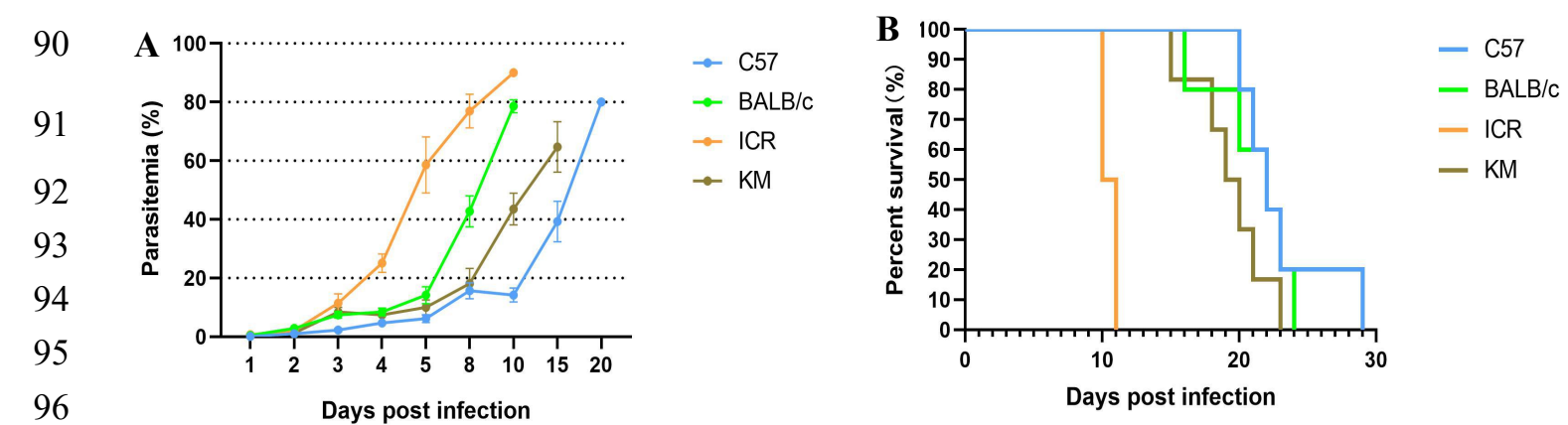

FIG 1: Parasitemia and survival curves in C57BL/6, BALB/c, ICR and KM mice following $\mathrm{PbK} 173$ infection. A: The percentage of parasitemia is presented as the arithmetic mean of each mouse strain \pm SD. B: Survival of mice without treatment $(n=6)$ as a function of days post infection with PbK173.

The combination of different mouse strains and parasites resulted in different disease outcomes following infection. BALB/c, ICR and KM mice developed infection with parasites observed in the blood as early as $1 \mathrm{dpi}$, whereas C57 mice converted at 2 dpi. Parasitemia was progressive in all groups (Fig. 1A). On 5 dpi, the parasitemia in ICR mice was $58.6 \%, 90 \%$ on the $8 \mathrm{dpi}$, and all animals died between 9-11 dpi (Fig. 1B). In BALB/c mice, parasitemia approached $50 \%$ by 8 dpi, and peaked at $80 \%$ on $10 \mathrm{dpi}$. The BALB/c mice all succumbed between 16-24 dpi. On the 15th day, the highest parasitemia of the $\mathrm{KM}$ mice was $65 \%$, and the animals all died between 15-23 dpi. The parasitemia of C57 mice was close to $50 \%$ on the 17 th day, and the highest parasitemia reached $80 \%$ on the 20th day. All C57 mice died from malaria by 29 dpi.

It was observed that C57 mice were more resistant to infection than the other strains examined, as evidenced by the latest peak parasitemia and prolonged survival. The highest parasitemia of KM mice was the lowest observed, but its survival was shorter than that of C57BL/6 mice. The highest parasitemia of ICR mice was higher than other strains, although these mice succumbed the fastest.

\section{Hematological Parameters}

In this study, $\mathrm{RBC}$ counts (mean $\pm \mathrm{SD}, 10^{12} / \mathrm{L}$ ) for uninfected control mice were as follows: C57BL/6 (10.01 \pm 0.25$), \quad \mathrm{BALB} / \mathrm{c} \quad(7.93 \pm 1.01), \quad \operatorname{ICR}(8.16 \pm 0.16), \quad \mathrm{KM}$ (8.64 \pm 0.29$)$. These values are within normal ranges, as reported previously. By 5 dpi,, 
123 all strains of mice presented with anaemia, thrombocytopaenia, and leukocytosis

124 (Table 1).

125 Malaria infections induce lymphocytopenia and an increase in neutrophils, which is 126 indicative of systemic inflammation (16). In all 4 strains of mice, the percentages of

127 lymphocytes decreased compared to the baseline values starting from 1 dpi. In ICR 128 mice, the decrease progressed significantly over the first 3 days. The 129 lymphocytopenia progressed slowly in BALB/c and KM mice on the 2nd-3rd day of 130 infection (Fig. 2A). In all mice, the percentages of neutrophils increased relative to 131 uninfected control mice starting from 1 dpi (Fig. 2B).

133

134

135

136

137

138

139

140

141

142

143

144

145

146

147
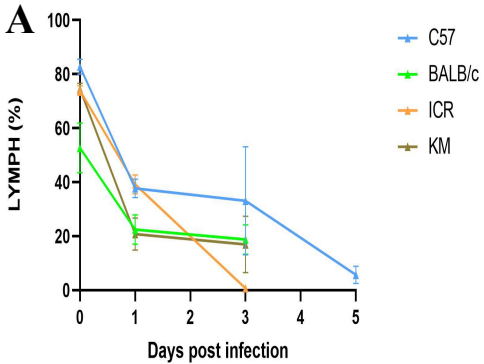
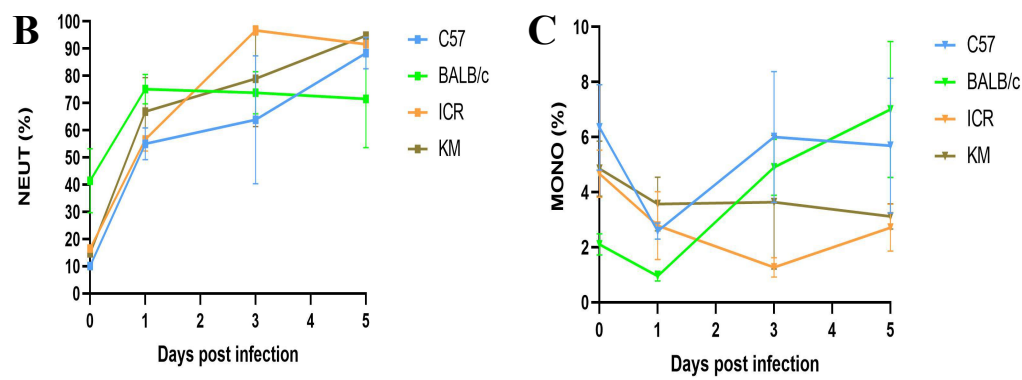

FIG 2: Effects of PbK173 infection on hematological parameters in C57BL/6, BALB/c, ICR and KM mice. A: Lymphocytes B: Neutrophils C: Monocytes.

The percentages of monocytes decreased compared with baseline values on at $1 \mathrm{dpi}$ for all infected groups. But on $5 \mathrm{dpi}$, the percentages of monocytes in BALB/c $(7.00 \pm 2.46, p<0.05)$ and $\mathrm{C} 57 \mathrm{BL} / 6(5.68 \pm 2.45, p>0.05)$ mice were increased.

In contrast, monocyte counts decreased in ICR $(2.71 \pm 0.85, p<0.05)$ and KM $(3.11 \pm 0.46, p<0.05)$ mice (Fig. 2C). 
Table 1: Effects of PbK173 infection on some hematological parameters in infected mice on 5 dpi.

\begin{tabular}{|c|c|c|c|c|c|c|c|c|}
\hline \multirow{2}{*}{$\begin{array}{l}\text { Hematological } \\
\text { parameters }\end{array}$} & \multicolumn{2}{|c|}{$\mathrm{C} 57 \mathrm{BL} / 6$} & \multicolumn{2}{|c|}{$\mathrm{BALB} / \mathrm{c}$} & \multicolumn{2}{|c|}{ ICR } & \multicolumn{2}{|c|}{ KM } \\
\hline & Uninfected & Infected & uninfected & infected & uninfected & infected & uninfected & infected \\
\hline $\operatorname{PLT}\left(10^{9} / \mathrm{L}\right)$ & $1278.83 \pm 89.60$ & $285.00 \pm 34.88 \downarrow * * *$ & $1310.50 \pm 57.76$ & $312.33 \pm 19.59 \downarrow * * *$ & $1635.67 \pm 68.14$ & $296.00 \pm 33.80 \downarrow^{* * *}$ & $1476.17 \pm 99.99$ & $341.33 \pm 31.87 \downarrow * * *$ \\
\hline $\operatorname{RBC}\left(10^{12} / \mathrm{L}\right)$ & $10.01 \pm 0.25$ & $7.75 \pm 0.62 \downarrow * * *$ & $7.93 \pm 1.01$ & $6.62 \pm 0.37 \downarrow^{*}$ & $8.16 \pm 0.16$ & $3.39 \pm 0.35 \downarrow^{* * *}$ & $8.64 \pm 0.29$ & $4.44 \pm 0.34 \downarrow * * *$ \\
\hline $\mathrm{HGB}(\mathrm{g} / \mathrm{L})$ & $149.67 \pm 2.66$ & $113.83 \pm 8.45 \downarrow * * *$ & $132.33 \pm 12.07$ & $101.50 \pm 4.42 \downarrow *$ & $137.17 \pm 4.26$ & $60.00 \pm 6.96 \downarrow * * *$ & $129.67 \pm 5.98$ & $68.83 \pm 4.92 \downarrow * * *$ \\
\hline HCT (\%) & $47.23 \pm 0.96$ & $37.78 \pm 3.03 \downarrow * * *$ & $40.40 \pm 3.28$ & $32.58 \pm 1.33 \downarrow *$ & $42.48 \pm 1.10$ & $21.27 \pm 2.19 \downarrow * * *$ & $42.67 \pm 2.02$ & $24.77 \pm 1.86 \downarrow * * *$ \\
\hline MCV (fL) & $46.52 \pm 0.43$ & $48.40 \pm 0.71 \uparrow * * *$ & $45.02 \pm 0.67$ & $49.22 \pm 1.48 \uparrow *$ & $51.77 \pm 1.33$ & $62.72 \pm 3.15 \uparrow * * *$ & $48.75 \pm 0.83$ & $56.26 \pm 1.12 \uparrow * * *$ \\
\hline $\mathrm{MCH}(\mathrm{pg})$ & $14.71 \pm 0.07$ & $14.56 \pm 0.24$ & $14.73 \pm 0.15$ & $15.46 \pm 0.63 \uparrow *$ & $16.86 \pm 0.35$ & $17.55 \pm 0.76$ & $15.18 \pm 0.35$ & $15.75 \pm 0.12 \uparrow *$ \\
\hline $\mathrm{MCHC}(\mathrm{g} / \mathrm{L})$ & $316.83 \pm 2.04$ & $301.17 \pm 2.14 \downarrow * * *$ & $327.17 \pm 4.35$ & $310.50 \pm 5.17 \downarrow * * *$ & $321.67 \pm 3.26$ & $283.83 \pm 5.49 \downarrow * * *$ & $310.67 \pm 3.38$ & $279.00 \pm 5.66 \downarrow * * *$ \\
\hline RDW-CV (\%) & $17.35 \pm .26$ & $16.20 \pm 0.83 \downarrow^{*}$ & $19.03 \pm 0.99$ & $16.72 \pm 0.92 \downarrow *$ & $15.85 \pm 0.32$ & $19.97 \pm 1.21 \downarrow *$ & $16.75 \pm 0.57$ & $15.83 \pm 1.64$ \\
\hline RDW-SD (fL) & $22.80 \pm 0.59$ & $24.50 \pm 1.16 \uparrow^{*}$ & $25.82 \pm 2.22$ & $26.87 \pm 1.49$ & $26.70 \pm 0.84$ & $41.11 \pm 4.13 \uparrow * * *$ & $27.27 \pm 0.74$ & $31.98 \pm 1.85 \uparrow * * *$ \\
\hline WBC $\left(10^{9} / \mathrm{L}\right)$ & $2.74 \pm 0.39$ & $5.84 \pm 2.16 \uparrow *$ & $4.37 \pm 0.93$ & $8.64 \pm 1.95 \uparrow *$ & $2.52 \pm 0.35$ & $5.63 \pm 1.64 \uparrow *$ & $1.65 \pm 0.30$ & $3.45 \pm 0.43 \uparrow * * *$ \\
\hline NEUT (\%) & $10.13 \pm 0.4$ & $88.33 \pm 5.83 \uparrow * * *$ & $32.68 \pm 9.50$ & $76.53 \pm 10.66 \uparrow * * *$ & $16.50 \pm 1.07$ & $91.65 \pm 2.59 \uparrow * * *$ & $14.78 \pm 1.31$ & $94.77 \pm 1.04 \uparrow * * *$ \\
\hline LYMPH (\%) & $82.80 \pm 2.78$ & $5.71 \pm 3.13 \downarrow * * *$ & $52.68 \pm 9.16$ & $---\downarrow * * *$ & $73.98 \pm 1.77$ & $---\downarrow * * *$ & $74.57 \pm 2.09$ & $---\downarrow * * *$ \\
\hline MONO (\%) & $6.35 \pm 1.55$ & $5.68 \pm 2.45$ & $2.10 \pm 0.38$ & $7.00 \pm 2.46 \uparrow^{*}$ & $4.66 \pm 0.85$ & $2.71 \pm 0.85 \downarrow^{*}$ & $4.85 \pm 1.01$ & $3.11 \pm 0.46 \downarrow^{*}$ \\
\hline EO (\%) & $1.47 \pm 0.67$ & $0.47 \pm 0.38 \downarrow^{*}$ & $2.13 \pm 0.59$ & $1.33 \pm 0.68$ & $4.06 \pm 0.53$ & $3.98 \pm 2.73$ & $4.60 \pm 1.66$ & $0.71 \pm 0.24 \downarrow^{*}$ \\
\hline BASO (\%) & $0.32 \pm 0.23$ & $0.63 \pm 0.23$ & $0.16 \pm 0.05$ & $0.38 \pm 0.04 \uparrow *$ & $0.25 \pm 0.20$ & $0.45 \pm 0.08$ & $0.51 \pm 0.17$ & $0.58 \pm 0.20$ \\
\hline
\end{tabular}

Values are given as mean $\pm \mathrm{SD}, \mathrm{n}=6 . *$ and $* * *$ indicate $p<0.05$ and $p<0.001$ compared with the uninfected group, respectively 


\section{Gross and histopathologic analysis of the spleen}

134 The spleen is an important site of erythropoiesis, the clearance of infected RBCs

135 (iRBCs), and immune system activation in response to blood-stage malaria (17). In

136 the present study, the body weight of infected mice was observed to decline following infection with PbK173. The spleen weight of infected groups was observed to increase beginning at $3 \mathrm{dpi}$. In response to infection, all mice experienced significant splenomegaly, but the splenic index was significantly higher in infected BALB/c

140 mice.

141 A

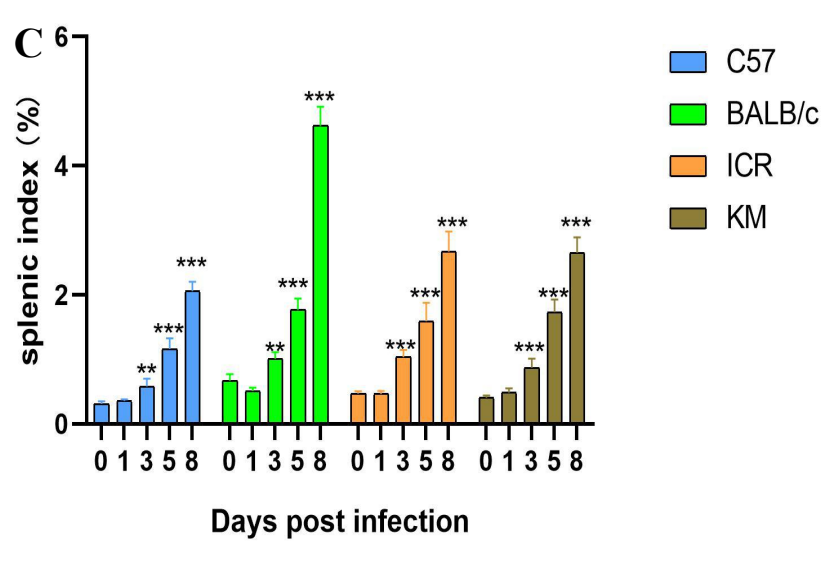

FIG 3: The change in body weight (A) and spleen weight (B) in the four strains of mice, spleen weights were normalized to the weight of uninfected groups (\%). C: Splenic index in uninfected and PbK173 infected mice. Spleen weights of infected mice were determined on days 3,5 , and 8 post infection. The splenic index was determined as the ratio of spleen weight to body weight. All data are presented as mean $\pm \mathrm{SD}, \mathrm{n}=6 . * *$ and $* * *$ indicate statistical significance at $p<0.01$ and $p<0.001$ compared with the uninfected group, respectively.
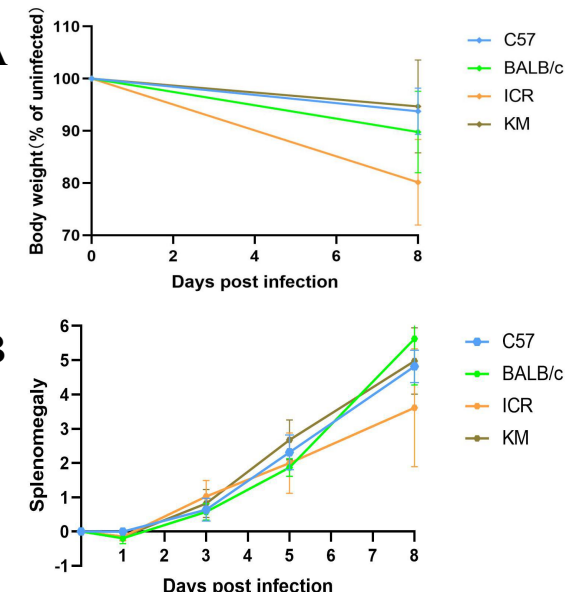

$-\mathrm{C} 57$

$\rightarrow$ BALB

$\rightarrow$ KM 


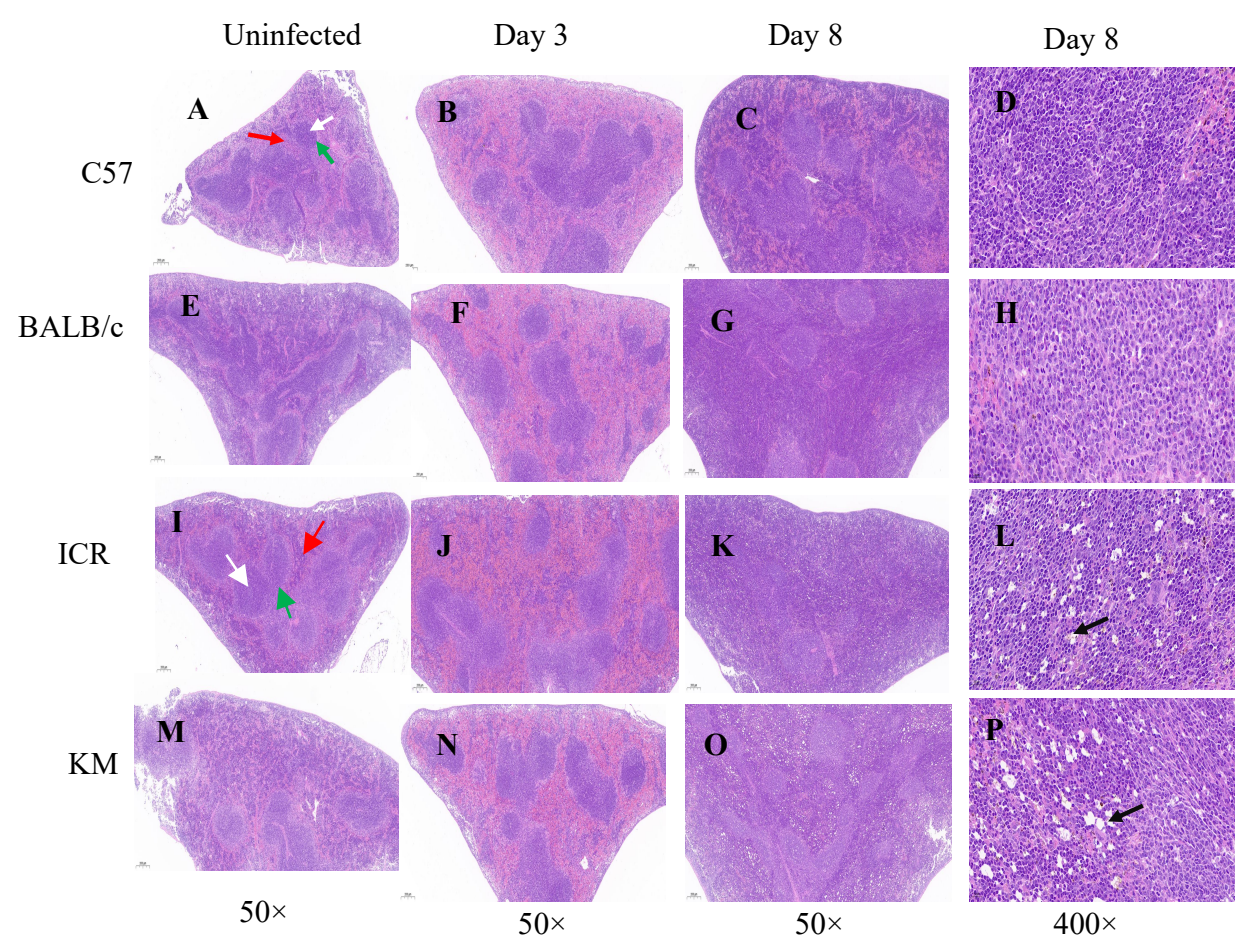

FIG 4: H\&E stained sections of spleen from infected or uninfected mice. white arrows: white pulp; red arrows: red pulp; green arrows: marginal zone; black arrows highlight vacuolation.

Figure 4 shows the histopathological sections of the spleen tissue. A clear distinction between the red and white pulp, resting follicles, and marginal zones were evident in the spleen of normal uninfected control mice (Fig. 4: A, E, I, M). Severe congestion and enlarged red pulp was observed in spleens of infected mice at $3 \mathrm{dpi}$ (Fig. 4: B, F, J, N). To a similar all mouse strains examined, increases in red and white pulp cellularity was observed, and the clear marginal zones surrounding follicles became inapparent (except in C57BL/6) at 8 dpi (Fig. 4: C, G, K, O). Furthermore, extensive vacuolation in the red pulp at 8 dpi was observed in spleens from ICR and KM mice (Fig. 4: L, P). 
uninfected

206

207

208

209

210

211

$212 \mathrm{BALB} / \mathrm{c}$

213

214

215

216

217

218

219

220

221

222

223

224

225

226

227

228

229

230

231

232

233

234

235

236

237
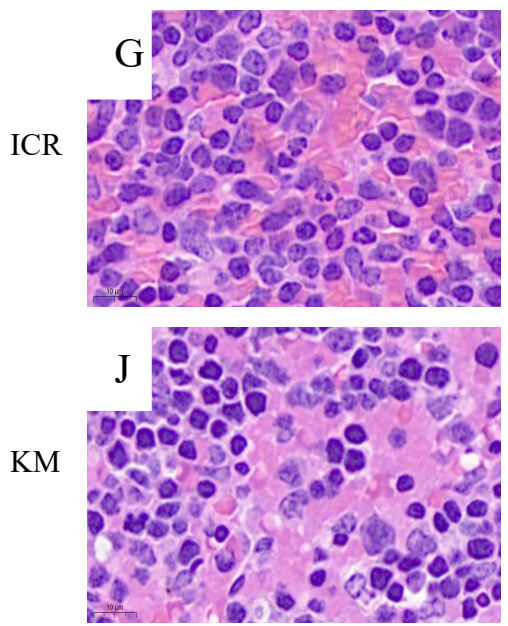
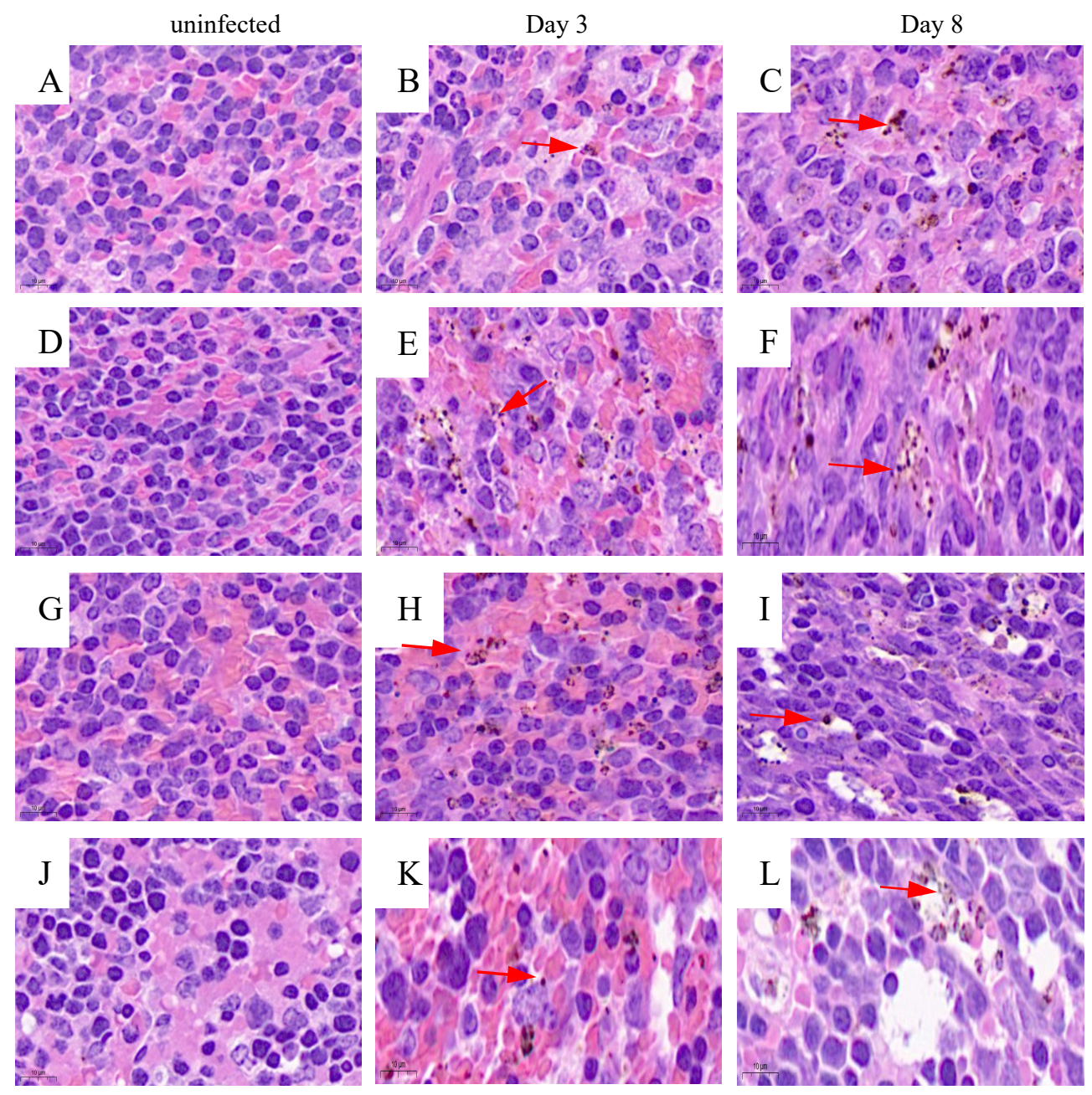

FIG 5: H\&E staining of spleen from control and PbK173 infected mice (1000×). Red arrows indicate malarial pigments, which appear as small brown punctate staining.

Spleen sections were prepared and examined via bright-field microscopy coupled with hematoxylin and eosin (H\&E) staining (Fig. 5). Parasite pigments in the pulp histiocytes and sinusoidal lining cells were observed at 3 dpi in all PbK173 infected mice. The extent of malaria pigmentation in the spleen is correlated with high parasitemia. The spleens of $\mathrm{C} 57 \mathrm{BL} / 6, \mathrm{BALB} / \mathrm{c}, \mathrm{ICR}$, and $\mathrm{KM}$ mice filtered late trophozoite stages as well as a fraction of earlier ring-stage parasites out of the blood at 3 dpi (Fig. 5: B, E, H, K). However, KM mice only retained the late trophozoite stage on day 8 (Fig. 5I). This phenomenon may be due to changes of the splenic structure, which could have resulted in alterations to the filtering function of the spleen. Transformations in the red pulp and splenic vasculature may modulate the mechanical retention threshold and regulate the microcirculatory trapping of blood 
242 cells in the spleen.

\section{Analysis of Splenocyte Subsets}
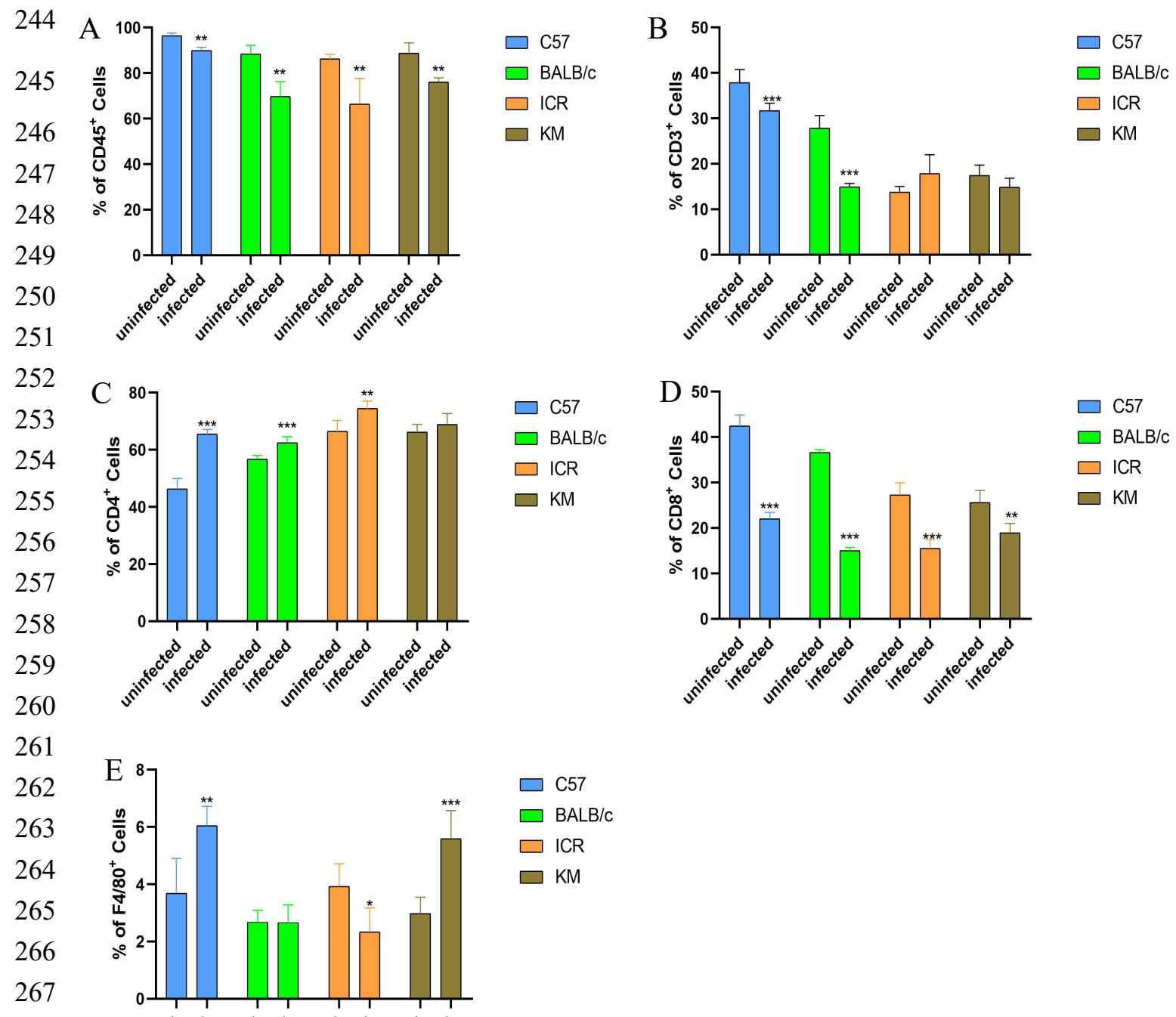

FIG 6: Flow cytometry analysis of splenocyte subsets at 8 dpi. Splenocytes of mice infected with parasites were incubated with the required antibodies according to the manufacture's protocol for antibody dilution, incubation duration, etc., and were analyzed in a CytoFLEX flow cytometer. *, ** and *** indicate statistical significance at $p<0.05, p<0.01$ and $p<0.001$ compared with the uninfected group,

Next, the distribution of macrophage and $\mathrm{T}$ lymphocyte subpopulations were analyzed. Using single-cell suspensions from PbK173 infected or uninfected control spleens, flow cytometry was performed to quantify total leukocytes (CD $45^{+}$cells), total $\mathrm{T}$ lymphocytes $\left(\mathrm{CD} 45^{+} \mathrm{CD} 3^{+}\right.$cells), $\mathrm{T}$ cell subsets $\left(\mathrm{CD} 4^{+}\right.$and $\mathrm{CD} 8^{+}$cells $)$, and 
monocytes/macrophages $\left(\mathrm{CD} 45^{+} \mathrm{F} 4 / 80^{+}\right.$cells) (Fig. 6). A significant decrease in total leukocyte in both $\mathrm{C} 57 \mathrm{BL} / 6, \mathrm{BALB} / \mathrm{c}, \mathrm{ICR}$ and $\mathrm{KM}$ infected mice $(p<0.01)$ was observed (Fig. 6A). The data also indicated a significant decrease in the percentages of the T lymphocytes $\left(\mathrm{CD}^{+}\right.$cells, except ICR and KM infected mice) (Fig. 6B) and $\mathrm{CD}^{+}$cells (Fig. 6D), while the percentages of $\mathrm{CD}^{+}$cells (Fig. 6C) in both $\mathrm{C} 57 \mathrm{BL} / 6$, $\mathrm{BALB} / \mathrm{c}, \mathrm{ICR}$ and $\mathrm{KM}$ infected mice increased.

The trends in macrophage percentages differed between the 4 strains of mice. The percentage of macrophages did not change significantly in BALB/c infected mice. A decrease in the percentage of macrophages was however observed in the infected ICR mice. Conversely, a significant increase in the percentages of the macrophages in $\mathrm{C} 57 \mathrm{BL} / 6$ and $\mathrm{KM}$ infected mice as compared to uninfected mice was observed (Fig. $6 \mathrm{E})$.
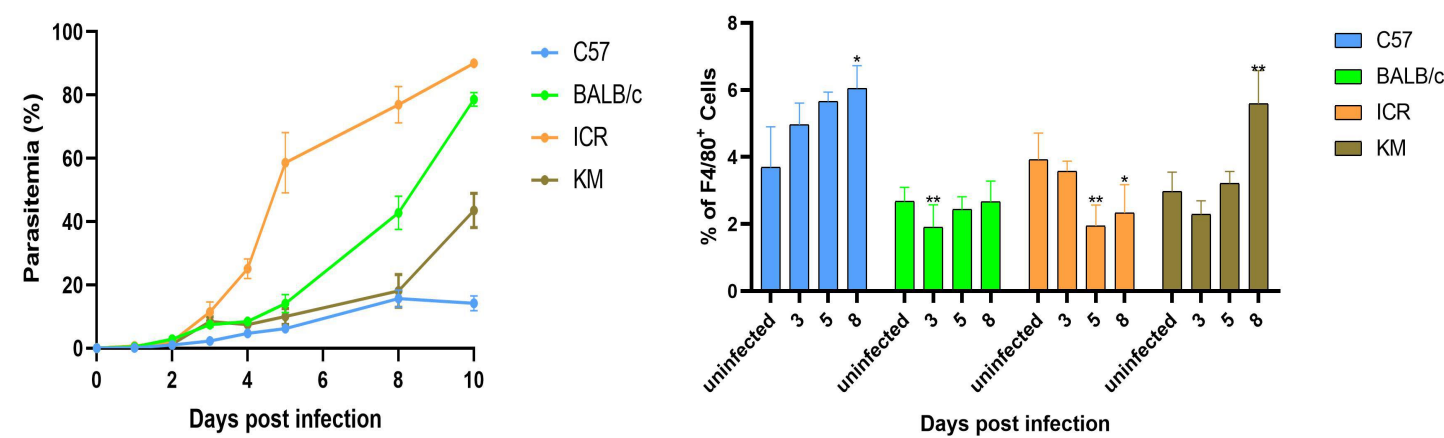

FIG 7: Parasitemia and flow cytometry analysis of macrophages in C57BL/6, BALB/c, ICR and KM mice over the course of PbK173 infection. ${ }^{*}$ and $* *$ indicate $p<0.05, p$ $<0.01$ compared with the uninfected group, respectively.

Splenic red pulp macrophages, located between the splenic cords and venous sinuses, are well positioned to clear iRBCs and are important for controlling blood-stage malaria (18). In the present study, after infection with PbK173, the percentages of macrophages in the spleen of C57BL/6 mice exhibited the greatest increase of all the mouse strins (Fig. 7B), and the parasitemia progressed the slowest compared to the other mouse strains (Fig. 7A).

The percentage of macrophages in the spleen of KM mice was higher than uninfected group on 8 dpi. The spleens in $\mathrm{KM}$ mice exhibited structural disorganization and remodeling, which likely affected the mechanical retention threshold. As a result, only late trophozoite stages were retained, which led to a 
316 significantly higher parasitemia in $\mathrm{KM}$ than $\mathrm{C} 57 \mathrm{BL} / 6$ mice. The percentages of

317 macrophages in ICR infected mice were lower than uninfected mice, and the 318 parasitemia was higher than other strains during the course of PbK173 infection (Fig.

$3197)$.

320 These data show that the rate of splenic mechanical filtration and the splenic macrophages may be important factors in determining an individual's total parasite burden and potentially influencing the pathogenesis of malaria, and different genetic backgrounds of mice have different mechanisms for controlling malaria infection in the spleen.

\section{DISCUSSION}

In this study, the survival time of mice infected with PbK173 varied, although the infection was uniformly lethal. Mice of the C57BL/6 strain were the most resistant, while ICR mice were the most susceptible. Both $\mathrm{BALB} / \mathrm{c}$ and $\mathrm{KM}$ mice were intermediate.

331 Changes in blood cell counts are characteristic of plasmodium infection. Haematological changes during the course of a malaria infection, such as anaemia, thrombocytopaenia, leukocytosis, and leucopenia are defining. Malaria infections also induce lymphocytopenia, which is accompanied by an increase in neutrophil count, and is a sign of systemic inflammation. Neutrophils (also known as polymorphonuclear cells) are the most common white blood cell in the body (19) and are one of the immune system's first lines of defense against infection. They can neutralize pathogens through several mechanisms, including phagocytosis, the production of reactive oxygen species (ROS) and other antimicrobial products, or by the formation of neutrophil extracellular traps (NETs) (20). Additionally, they also play a role in the activation and regulation of the immune response through the secretion of cytokines and chemokines (21), and the presentation of foreign antigens

343 (22). A substantial body of work has been conducted to investigate the role of 344 neutrophils in malaria. It has been determined that during infection, neutrophils are activated and are capable of clearing malaria parasites by a number of mechanisms. 
In this experiment, the above hematological parameters of different mouse strains exhibited similar trends with respect to changes in the parameters, although the changes in the percentages of monocytes varied. Cells of the monocyte/macrophage lineage are one of the main sources of cytokines in malaria-infected individuals. While some of the cytokines may be of importance for parasite clearance (eg, IL-12) (23), others may be major contributors to disease progression (eg, TNF) (24). Monocytes recognize Plasmodium falciparum biological products and Pf-infected erythrocytes directly through pattern recognition receptors (PRR) (25), as well as complement- or IgG-opsonized erythrocytes and parasite components via complement receptors and Fc $\gamma$ receptors (26). Activated monocytes have several important effector functions in the host defense against malaria, including phagocytosis (27), cytokine production (28), and modulation of adaptive immune responses $(29,30)$. At 5 dpi, compared with the uninfected groups, the percentages of monocytes in BALB/c and C57BL/6 mice were elevated, whereas the values in ICR and KM mice were reduced. Conversely, the parasitemia in ICR mice was significantly higher than KM mice. These results indicate that perhaps the immune cells in peripheral blood are only part of the host response necessary to control plasmodium infection.

The spleen is a key site for removal of parasitized red blood cells, generation of immunity and production of new red blood cells during malaria. The importance of the spleen for the control of malaria was confirmed by studying the response of splenectomized humans and rodents to infection. Humans with acute P. falciparum malaria who had previously undergone splenectomy had decreased clearance of iRBCs from the circulation (31). The mice subjected to partial splenectomy presented a level of parasites similar to that of non-splenectomized mice, while the animals subjected to full splenectomy had twice the amount of circulating parasites (32). Furthermore, parasite clearance after drug treatment was delayed in splenectomized patients, with RBCs containing dead parasites being retained in the circulation for prolonged periods, compared with individuals with a functional spleen (33).

374 During acute attacks of malaria, splenomegaly is one of the typical signs of malaria, 375 and the degree of splenomegaly often impacts the host's ability to mount a successful 
response to the parasite (34). Besides an increase in the organ volume and mass, the spleen also exhibits structural disorganization and remodeling. These changes include expansion of the red pulp, transient loss of the marginal zone, increased vasculature, and activation of barrier cells, which may establish a blood-spleen barrier that can drastically alter splenic blood circulation $(35,13,36)$. In this study, the spleen index of infected groups was observed to increase from $3 \mathrm{dpi}$. Severe congestion and enlarged red pulp was evident in the infected mice. By 8 dpi, infection-induced increases in red and white pulp cellularity and the marginal zones surrounding follicles disappeared in all strains of mice examined. However, the spleens of $\mathrm{C} 57 \mathrm{BL} / 6$ and BALB/C infected mice maintain their structural integrity integrity, although the spleen index of BALB/C changed the most. The spleen of ICR and KM mice exhibited severe vacuolation, and the splenic structure was highly atypical, with many of the features absent at this time. This could be a result of the spleen structures of mice with different genetic backgrounds possessing different tolerances and pathologies to infection with malaria.

During the erythrocytic stages of malaria infection, the spleen plays a critical role in the host immune response. Elimination of infected erythrocytes occurs through activation of cellular and humoral immune responses, and through mechanical filtration. White and red pulp structures have specific functions in the human spleen. The white pulp is a major control center for the humoral immune response, especially to circulating antigens. The red pulp exerts a unique and subtle control of the surface integrity and biomechanical properties of erythrocytes. To be left in circulation, RBCs must be fit enough to cross a very specific structure of red pulp sinuses, the interendothelial slit (IES). Older erythrocytes, or those modified by innate or acquired conditions, are eventually retained in the splenic red pulp and processed by red pulp macrophages (RPMs) (37).

During asexual replication (including the sequential ring, trophozoite, and schizont stages), parasite maturation induces changes in the host RBC with novel proteins synthesis $(38,39)$. As the parasite develops, the infected RBC (iRBC) loses its biconcave shape and progressively becomes spherical and rigid (40). Furthermore, the 
surface area-to-volume ratio decreases, the shear elastic modulus of the plasma membrane, and the cellular viscosity increase (41). The loss of RBC deformability is not limited to mature stages, but starts soon after parasite invasion. During the ring stage (within the first 16-24 h after RBC invasion), iRBC undergo up to $9.6 \%$ surface area loss $(42,43)$. The altered deformability of the plasmodium-infected RBC may result in increased retention in the spleen. More than $50 \%$ of ring-iRBC are retained upon ex vivo transfusion through human spleens (43). These retention and accumulation processes stem from the splenic screening of RBC deformability (44). However, no direct evidence exists demonstrating the correlation among the rate of splenic mechanical filtration, macrophages, and infection severity. In this study, at 3 days post $\mathrm{PbK} 173$ infection, malaria pigments were observed in the red pulp in great abundance. The pigments consisted of parasites in the ring and trophozoite stages.

In a systemic pathological study of cerebral malaria in African children, enlarged spleens and abundant malaria pigments in splenic macrophages were observed in the majority of the 103 fatal cases. These observations point to an important role of the spleen in parasite control. In this study, the number of macrophages in the spleen of C57BL/6 mice infected with PbK173 was higher than that in uninfected controls, and the parasitemia was lower than other strains during. The percentage of macrophages in the spleen of infected ICR mice was lower than the uninfected group, and the parasitemia increased the fastest. During the infection period, the ratio of macrophages in the spleen of BALB/c mice was not significantly different from that of the uninfected group. The growth rate of the parasitemia was lower than in ICR mice, but higher than that of C57BL/6 mice. This can be explained by the fact that macrophages complement the filtering function of the spleen to control parasitic infections.

Artemisinin-based combination therapies (ACTs) are the standard of care to treat uncomplicated falciparum malaria. However, resistance to artemisinins was first reported through observations of a 100-fold reduction in parasite clearance rate in Pailin, Western Cambodia, in 2009 (45). The clearance rate is defined as a parasite 
clearance half-life $\geqslant 5$ hours following treatment with artesunate monotherapy or an ACT (46). Unfortunately, this has become a common issue in Southeast Asia (SEA). Artemisinin resistance has been associated in with multiple nonsynonymous single nucleotide polymorphisms (NS-SNPs) in the propeller domain of the gene encoding the P. falciparum K13 protein (K13PD) $(47,48)$. In Africa, significantly prolonged clearance has yet to be observed (49).

The delayed clearance phenotype initially observed in SEA does not represent "drug resistance" in the traditional use of the term. Antimicrobial drug resistance is typically defined by quantifiable shifts in the cytostatic or cytocidal potency of the antimicrobial drug. It is important to emphasize that as a 3-day course of artemisinin has never been considered a curative regimen. Artemisinins remain effective, even if they require a longer treatment course or other modifications to the combination-treatment regimen (50). It is not clear if a delay in parasite clearance with artemisinin treatments be defined as drug "resistance."

The spleen controls malaria infection by removing the plasmodium from the blood. Splenic functions of mice with different genetic backgrounds vary, and when splenomegaly occurs after malaria infection, the prognosis is not favorable. However, it is not clear if splenomegaly affects the organ's ability to clear parasites from the blood.

In summary, the filtering function of the spleen and the expression of macrophages may also be involved in the control of malaria infection. Mice with different genetic backgrounds have different filtering functions in the spleen from the expression of macrophages. The tolerance is also different, which may be the reason for the differential susceptibility of different strains of mice to PbK173.

\section{MATERIALS AND METHODS}

\section{Parasite strains and culturing conditions}

Plasmodium berghei K173, a gift from Dr. Dai of Chengdu University of TCM, was serially passaged in vivo in mice. Infected blood was harvested at day 5-7 post-infection and stored as frozen stabilates in Alsever's solution containing $10 \%$ 
glycerol.

\section{Mice and infection}

Male C57BL/6, BALB/C, ICR, and KM wild-type (WT) mice (18 22g,) were used in this study. Animals were purchased from Weitonglihua (Beijing, China). A total of 6 mice per group were infected intraperitoneally with $10^{7} \mathrm{PbK} 173$-infected RBCs and were provided water and standard laboratory mouse chow diet ad libitum throughout the experiment. All mice were housed in pathogen-free animal facilities at the Institute of Chinese Materia Medica, China Academy of Chinese Medical Sciences.

\section{Measurement of hematologic parameters and parasitemia}

Complete blood counts were obtained with a XN-1000V $\left[\mathrm{B}_{1}\right]$ blood analyzer (Sysmex, Japan). Parasitemia (i.e., the percentage of infected RBCs) was assessed at each time point by microscopic counts of thin blood smears stained with Giemsa solution (Sigma -Aldrich, USA).

\section{Isolation of immune cells from mouse spleen}

Spleen samples were surgically removed and weighed in a sterile hood. One part of each spleen sample was removed and fixed 4\% paraformaldehyde for histopathologic examination, and the remainder was used for isolation of splenocytes.

Spleens harvested under aseptic conditions were ground into small pieces and passed through a sterilized 200 mesh to prepare crude splenocyte suspensions at room temperature. Samples were then centrifuged at $1000 \mathrm{rpm}$ for $8 \mathrm{~min}$ at $4{ }^{\circ} \mathrm{C}$, and the remaining splenocyte suspension was re-suspended in red blood cell Lysis Buffer (Thermo Fisher Scientific, USA). After a 10 min treatment, $1 \times$ PBS was added to dilute the samples, and then centrifuged at $1000 \mathrm{rpm}$ for $8 \mathrm{~min}$ at $4{ }^{\circ} \mathrm{C}$. The pelleted splenocytes in each group were washed twice and adjusted to concentrations of $5 \times$ $10^{6}$ cells $/ \mathrm{mL}$ with $1 \times$ PBS.

\section{Analysis of Splenocyte Subsets}

The single cell splenocyte suspensions were stained with the following anti-mouse antibodies: CD45-KO525, CD3-FITC, CD4-PC5.5, CD8-APC, and F4/80-PE (Proteintech Group, USA). Splenocytes were incubated with monoclonal antibodies in 
494 the dark for $30 \mathrm{~min}$ at $4{ }^{\circ} \mathrm{C}$. According to the manufacturer's instructions, the specificity of labeling was confirmed by isotype-matched antibody staining controls. The labeled cells were analyzed using a CytoFLEX flow cytometer (Beckman coulter, USA).

\section{Histological examination}

Spleen tissues were fixed in 4\% paraformaldehyde, dehydrated through graded alcohol, embedded in paraffin, sectioned at a thickness of $3 \mu \mathrm{m}$, and then stained with hematoxylin \& eosin (H\&E) and Giemsa solution according to standard procedures. Then, the stained slides were mounted in neutral balsam and covered with coverslips. Histopathologic changes were observed by light microscopy (BX43F Olympus, Japan).

\section{Statistical Analysis}

Data were analyzed using SPSS 19.0 (IBM,USA) and reported as mean \pm SD. Significant differences between groups were analyzed using one-way ANOVA, and are designated as follows: $* p<0.05, * * p<0.01$ and $* * * p<0.001$ relative to the uninfected control groups. Survival curves were calculated using GraphPad Prism 8.0 (GraphPad Software,USA).

\section{ETHIC STATEMENT}

513 Experimental protocols were approved by the Laboratory Animal Ethics Committee 514 of the Institute of Chinese Materia Medica, China Academy of Chinese Medical Sciences (license number SCXK 2016-0006).

\section{ACKNOWLEDGMENTS}

518 This research was funded by the National Natural Science Foundation of China 519 (81641002 and 81841001). We gratefully acknowledge the help from researchers at 520 the Tang Center for Herbal Medicine Research for providing experiment guidance.

521 We would also like to thank Dr. Dai from Chengdu University of TCM for providing the Plasmodium berghei K173 and providing technical guidance. 


\section{REFERENCES}

1. World Health Organization.World malaria report 2019[M]. Geneva:WHO Press, 2019.

2. Manjurano A, Sepúlveda N, Nadjm B, Mtove G, Wangai H, Maxwell C, Olomi R, Reyburn H, Drakeley CJ, Riley EM, Clark TG, \& in Collaboration With MalariaGEN. 2015. USP38, FREM3, SDC1, DDC, and LOC727982 Gene Polymorphisms and Differential Susceptibility to Severe Malaria in Tanzania. The Journal of infectious diseases, 212(7), 1129-1139. https://doi.org/10.1093/infdis/ jiv192.

3. Duffy F, Bernabeu M, Babar PH, Kessler A, Wang CW, Vaz M, Chery L, Mandala WL, Rogerson SJ, Taylor TE, Seydel KB, Lavstsen T, Gomes E, Kim K, Lusingu J, Rathod PK, Aitchison JD, Smith JD. 2019. Meta-analysis of Plasmodium falciparum var Signatures Contributing to Severe Malaria in African Children and Indian Adults. mBio, 10(2), e00217-19. https://doi.org/10.1128/mBio. 00217-19.

4. Siao MC, Borner J, Perkins SL, Deitsch KW, Kirkman LA. 2020. Evolution of Host Specificity by Malaria Parasites through Altered Mechanisms Controlling Genome Maintenance. mBio, 11(2), e03272-19. https://doi.org/10.1128/mBio. 03272-19.

5. Mackinnon MJ, Mwangi TW, Snow RW, Marsh K, Williams TN. 2005.

Heritability of malaria in Africa. PLoS medicine, 2(12), e340. https://doi.org/10.1371/journal.pmed.0020340.

6. White NJ. 2017. Malaria parasite clearance. Malaria journal, 16(1), 88. https://doi. org/10.1186/s12936-017-1731-1.

7. Aogo RA, Khoury DS, Cromer D, Elliott T, Akter J, Fogg LG, Nair AS, Liligeto UN, Soon M, Thomas BS, Pernold C, Romanczuk AS, Laohamonthonkul P, Haque A, Davenport MP. 2018. Quantification of host-mediated parasite clearance during blood-stage Plasmodium infection and anti-malarial drug treatment in mice. International journal for parasitology, 48(12), 903-913. https://doi.org/10.1016/j. ijpara.2018.05.010.

8. Crosby WH. Normal functions of the spleen relative to red blood cells: a review. Blood. 1959;14:399-408.

9. Nathan DG. 1969. Rubbish in the red cell. The New England journal of medicine, 281(10), 558-559. https://doi.org/10.1056/NEJM196909042811013

10. Finch CA, Harker LA, Cook JD. 1977. Kinetics of the formed elements of human blood. Blood, 50(4), 699-707.

11. Groom AC, Schmidt EE, MacDonald IC. 1991. Microcirculatory pathways and blood flow in spleen: new insights from washout kinetics, corrosion casts, and quantitative intravital videomicroscopy. Scanning microscopy, 5(1), 159-174.

12. Buffet PA, Milon G, Brousse V, Correas JM, Dousset B, Couvelard A, Kianmanesh R, Farges O, Sauvanet A, Paye F, Ungeheuer MN, Ottone C, Khun H, Fiette L, Guigon G, Huerre M, Mercereau-Puijalon O, David PH. 2006. Ex vivo perfusion of human spleens maintains clearing and processing functions. Blood, 107(9), 3745-3752. https://doi.org/10.1182/blood-2005-10-4094. 
13. Safeukui I, Correas JM, Brousse V, Hirt D, Deplaine G, Mulé S, Lesurtel M, Goasguen N, Sauvanet A, Couvelard A, Kerneis S, Khun H, Vigan-Womas I, Ottone C, Molina TJ, Tréluyer JM, Mercereau-Puijalon O, Milon G, David P H, Buffet P A. 2008. Retention of Plasmodium falciparum ring-infected erythrocytes in the slow, open microcirculation of the human spleen. Blood, 112(6), 2520-2528. https://doi.org/10.1182/blood-2008-03-146779.

14. Mohandas, N, Gallagher PG. 2008. Red cell membrane: past, present, and future. Blood, 112(10), 3939-3948. https://doi.org/10.1182/blood-2008-07-161166.

15. Groom C, Schmidt EE, MacDonald IC. 1991. Microcirculatory pathways and blood flow in spleen: new insights from washout kinetics, corrosion casts, and quantitative intravital videomicroscopy. Scanning microscopy, 5(1), 159-174.

16. Berens-Riha N, Kroidl I, Schunk M, Alberer M, Beissner M, Pritsch M, Kroidl A, Fröschl G, Hanus I, Bretzel G, von Sonnenburg F, Nothdurft HD, Löscher T, Herbinger KH. 2014. Evidence for significant influence of host immunity on changes in differential blood count during malaria. Malaria journal, 13, 155. https://doi.org/10.1186/1475-2875-13-155.

17. Lamikanra AA, Brown D, Potocnik A, Casals-Pascual C, Langhorne J, Roberts DJ. 2007. Malarial anemia: of mice and men. Blood, 110(1), 18-28. https://doi. org/10.1182/blood-2006-09-018069.

18. Borges da Silva H, Fonseca R, Pereira RM, Cassado A, Álvarez JM, D'Império Lima MR. 2015. Splenic Macrophage Subsets and Their Function during BloodBorne Infections. Frontiers in immunology, 6, 480. https://doi.org/10.3389/ fimmu.2015.00480.

19. Hsieh MM, Everhart JE, Byrd-Holt DD, Tisdale JF, \& Rodgers GP. 2007. Prevalence of neutropenia in the U.S. population: age, sex, smoking status, and ethnic differences. Annals of internal medicine, 146(7), 486-492. https://doi. org/ 10.7326/0003-4819-146-7-200704030-00004.

20. Kolaczkowska E, Kubes P. 2013. Neutrophil recruitment and function in health and inflammation. Nature reviews. Immunology, 13(3), 159-175. https://doi.org/ 10.1038/nri3399.

21. Tecchio C, Cassatella MA. 2016. Neutrophil-derived chemokines on the road to immunity. Seminars in immunology, 28(2), 119-128. https://doi.org/10.1016/ j.smim.2016.04.003.

22. Lin A, Loré K. 2017. Granulocytes: New Members of the Antigen-Presenting Cell Family. Frontiers in immunology, 8, 1781. https://doi.org/10.3389/ fimmu. 2017. 01781.

23. Malaguarnera L, Pignatelli S, Musumeci M, Simporè J, Musumeci S. 2002. Plasma levels of interleukin-18 and interleukin-12 in Plasmodium falciparum malaria. Parasite immunology, 24(9-10), 489-492. https://doi.org/10.1046/ j.1365-3024.2002.00485.x.

24. Schofield L, Hackett F. 1993. Signal transduction in host cells by a glycosylphosphatidylinositol toxin of malaria parasites. The Journal of experimental medicine, 177(1), 145-153. https://doi.org/10.1084/jem.177.1.145. 25. Gazzinelli RT, Denkers EY. 2006. Protozoan encounters with Toll-like receptor 
signalling pathways: implications for host parasitism. Nature reviews. Immunology, 6(12), 895-906. https://doi.org/10.1038/nri1978.

26. Silver KL, Higgins SJ, McDonald CR, Kain KC. 2010. Complement driven innate immune response to malaria: fuelling severe malarial diseases. Cellular microbiology, 12(8),1036-1045. https://doi.org/10.1111/j.1462-5822.2010.01492.x.

27. Ayi K, Patel SN, Serghides L, Smith TG, Kain KC. 2005. Nonopsonic phagocytosis of erythrocytes infected with ring-stage Plasmodium falciparum. Infection and immunity, 73(4), 2559-2563. https://doi.org/10.1128/IAI.73.4. 2559 -2563.2005 .

28. Gowda DC. 2007. TLR-mediated cell signaling by malaria GPIs. Trends in parasitology, 23(12), 596-604. https://doi.org/10.1016/j.pt.2007.09.003.

29. Scholzen A, Teirlinck AC, Bijker EM, Roestenberg M, Hermsen CC, Hoffman SL, Sauerwein RW. 2014. BAFF and BAFF receptor levels correlate with B cell subset activation and redistribution in controlled human malaria infection. Journal of immunology (Baltimore, Md. : 1950), 192(8), 3719-3729. https://doi.org/10. 4049/jimmunol.1302960.

30. Dobbs KR, Crabtree JN, Dent AE. 2020. Innate immunity to malaria-The role of monocytes. Immunological reviews, 293(1), 8-24. https://doi.org/10. 1111/imr. 12830.

31. Looareesuwan S, Suntharasamai P, Webster HK, Ho M. 1993. Malaria in splenectomized patients: report of four cases and review. Clinical infectious diseases: an official publication of the Infectious Diseases Society of America, 16(3), 361-366. https://doi.org/10.1093/clind/16.3.361.

32. Negreiros RM, Makimoto FH, Santana LL, Ferreira LC, Nakajima GS, Santos MC. 2009. Experimental splenectomies and malaria in mice. Acta cirurgica brasileira, 24(6), 437-441. https://doi.org/10.1590/s0102-86502009000600003.

33. Chotivanich K, Udomsangpetch R, McGready R, Proux S, Newton P, Pukrittayakamee S, Looareesuwan S, White NJ. 2002. Central role of the spleen in malaria parasite clearance. The Journal of infectious diseases, 185(10), 1538-1541. https://doi.org/10.1086/340213.

34. Cadman ET, Abdallah AY, Voisine C, Sponaas AM, Corran P, Lamb T, Brown D, Ndungu F, Langhorne J. 2008. Alterations of splenic architecture in malaria are induced independently of Toll-like receptors 2, 4, and 9 or MyD88 and may affect antibody affinity. Infection and immunity, 76(9), 3924-3931. https://doi.org/10. 1128/IAI.00372-08.

35. Urban BC, Hien TT, Day NP, Phu NH, Roberts R, Pongponratn E, Jones M, Mai NT, Bethell D, Turner GD, Ferguson D, White NJ, Roberts DJ. 2005. Fatal Plasmodium falciparum malaria causes specific patterns of splenic architectural disorganization. Infection and immunity, 73(4), 1986-1994. https://doi.org/10. 1128/IAI.73.4.1986-1994.2005.

36. Huang X, Huang S, Ong LC, Lim JC, Hurst RJ, Mushunje AT, Matsudaira PT, Han J, Preiser PR. 2015. Differential Spleen Remodeling Associated with Different Levels of Parasite Virulence Controls Disease Outcome in Malaria Parasite Infections. mSphere, 1(1), e00018-15. 
https://doi.org/10.1128/mSphere.00018-15.

37. Buffet PA, Safeukui I, Deplaine G, Brousse V, Prendki V, Thellier M, Turner GD, Mercereau-Puijalon O. 2011. The pathogenesis of Plasmodium falciparum malaria in humans: insights from splenic physiology. Blood, 117(2), 381-392. https://doi.org/10.1182/blood-2010-04-202911.

38. Gilson PR, Chisholm SA, Crabb BS, de Koning-Ward TF. 2017. Host cell remodelling in malaria parasites: a new pool of potential drug targets. International journal for parasitology, 47(2-3), 119-127. https://doi.org/10.1016/j.ijpara.2016.06.001.

39. Ndour PA, Larréché S, Mouri O, Argy N, Gay F, Roussel C, Jauréguiberry S, Perillaud C, Langui D, Biligui S, Chartrel N, Mérens A, Kendjo E, Ghose A, Hassan M, Hossain MA, Kingston H, Plewes K, Dondorp AM, Danis M, French Artesunate Working Group 2017. Measuring the Plasmodium falciparum HRP2 protein in blood from artesunate-treated malaria patients predicts post-artesunate delayed hemolysis. Science translational medicine, 9(397), eaaf9377. https://doi.org/10.1126/scitranslmed.aaf9377.

40. Cranston HA, Boylan CW, Carroll GL, Sutera SP, Williamson JR, Gluzman IY, Krogstad DJ. 1984. Plasmodium falciparum maturation abolishes physiologic red cell deformability. Science (New York, N.Y.), 223(4634), 400-403. https://doi.org/10.1126/science.6362007.

41. Herricks T, Antia M, Rathod PK. 2009. Deformability limits of Plasmodium falciparum-infected red blood cells. Cellular microbiology, 11(9), 1340-1353. https://doi.org/10.1111/j.1462-5822.2009.01334.x.

42. Safeukui I, Buffet PA, Perrot S, Sauvanet A, Aussilhou B. Dokmak S, Couvelard A, Hatem DC, Mohandas N, David PH, Mercereau-Puijalon O, Milon G. 2013. Surface area loss and increased sphericity account for the splenic entrapment of subpopulations of Plasmodium falciparum ring-infected erythrocytes. PloS one, 8(3), e60150. https://doi.org/10.1371/journal.pone.0060150.

43. Jauréguiberry S, Ndour PA, Roussel C, Ader F, Safeukui I, Nguyen M, Biligui S, Ciceron L, Mouri O, Kendjo E, Bricaire F, Vray M, Angoulvant A, Mayaux J, Haldar K, Mazier D, Danis M, Caumes E, Thellier M, Buffet P, French Artesunate Working Group 2014. Postartesunate delayed hemolysis is a predictable event related to the lifesaving effect of artemisinins. Blood, 124(2), 167-175. https://doi.org/10.1182/blood-2014-02-555953.

44. Depond M, Henry B, Buffet P, Ndour PA. 2020. Methods to Investigate the Deformability of RBC During Malaria. Frontiers in physiology, 10, 1613. https://doi.org/10.3389/fphys.2019.01613.

45. Dondorp AM, Nosten F, Yi P, Das D, Phyo AP, Tarning J, Lwin KM, Ariey F, Hanpithakpong W, Lee SJ, Ringwald P, Silamut K, Imwong M, Chotivanich K, Lim P, Herdman T, An SS, Yeung S, Singhasivanon P, Day NP, White NJ. 2009. Artemisinin resistance in Plasmodium falciparum malaria. The New England journal of medicine, 361(5), 455-467. https://doi.org/10.1056/NEJMoa0808859.

46. World Health Organization [20 January 2016]. Update on artemisinin and ACT resistance - September 2015. 
47. Conrad MD, Nsobya SL, Rosenthal PJ. 2019. The Diversity of the Plasmodium falciparum K13 Propeller Domain Did Not Increase after Implementation of Artemisinin-Based Combination Therapy in Uganda. Antimicrobial agents and chemotherapy, 63(10), e01234-19. https://doi.org/10.1128/AAC.01234-19.

48. Straimer J, Gnädig NF, Stokes BH, Ehrenberger M, Crane AA, Fidock DA. 2017. Plasmodium falciparum K13 Mutations Differentially Impact Ozonide Susceptibility and Parasite Fitness In Vitro. mBio, 8(2), e00172-17. https://doi.org/10.1128/mBio.00172-17.

49. Silva M, Ferreira PE, Otienoburu SD, Calçada C, Ngasala B, Björkman A, Mårtensson A, Gil JP, Veiga MI. 2019. Plasmodium falciparum K13 expression associated with parasite clearance during artemisinin-based combination therapy. The Journal of antimicrobial chemotherapy, 74(7), 1890-1893. https://doi.org/10.1093/jac/dkz098

50. Wang J, Xu C, Liao FL, Jiang T, Krishna S, Tu Y. 2019. A Temporizing Solution to "Artemisinin Resistance". The New England journal of medicine, 380(22), 2087-2089. https://doi.org/10.1056/NEJMp1901233. 